18

\title{
Исследование люминесцентных комплексов квантовых точек градиентного состава и наночастиц золота с молекулами карбоксилмеркаптановых кислот*
}

\author{
(C) Т.К. Кормилина ${ }^{1}$, Е.А. Степаниденко ${ }^{1}$, С.А. Черевков ${ }^{1}$, А. Дубовик ${ }^{1}$, В.Ю. Михайловский ${ }^{2}$, \\ А.В. Федоров ${ }^{1}$, Е.В. Ушакова ${ }^{1, \uparrow, ~ А . В . ~ Б а р а н о в ~}{ }^{1}$ \\ ${ }^{1}$ Университет ИТМО, \\ 197101 Санкт-Петербург, Россия \\ ${ }^{2}$ Санкт-Петербургский государственный университет, \\ 199034 Санкт-Петербург, Россия \\ `e-mail: el.ushakova@gmail.com
}

Поступила в редакцию 06.07.2018 г.

Исследовано взаимодействие полупроводниковых квантовых точек $\mathrm{CdZnSe} / \mathrm{ZnS}$ градиентного состава (КТ) и золотых наночастиц $(\mathrm{Au} \mathrm{HЧ})$ в коллоидных растворах. Показано, что благодаря замене лигандов на поверхности Au НЧ на молекулы карбоксилмеркаптановых кислот возможно получить комплексы связанных $\mathrm{Au}$ НЧ и гидрофобных КТ с поверхностью, очищенной от органических лигандов.

DOI: $10.21883 / O S .2018 .11 .46832 .198-18$

\section{Введение}

Развитие научного прогресса в сфере нанотехнологий в последние десятилетия дало нам эффективные материалы и системы с впечатляющими оптическими характеристиками. Полупроводниковые нанокристаллы и, в особенности квантовые точки (КТ), можно назвать главным современным материалом для оптоэлектроники и крайне важным инструментом в различных областях биохимии $[1,2]$. Наибольшая универсальность и эффективность обеспечиваются использованием квантовых точек смешанного химического состава, которые позволяют получить излучение на желаемой длине волны в сочетании с высокой химической стабильностью и квантовым выходом фотолюминесценции [3].

Крайне перспективным является наноинжиниринг новых многокомпонентных систем и выявление синергетических свойств наноструктурированных материалов, полученных из нанообъектов разной природы. В последние несколько лет эта стратегия активно применяется к полупроводниковым нанокристаллам и наночастицам благородных металлов [4]. Сочетание этих наноматериалов позволяет добиться усиления оптических откликов КТ за счет локальных электрических полей металлических наночастиц. Это свойство может быть применено в разработке многокомпонентных материалов с крайне высокой электрооптической функциональностью [5], востребованных для создания устройств фотокатализа, биологической визуализации и солнечной энергетики. Для успешной реализации этих направлений важно понимание факторов, влияющих на процессы

* International Conference „PCNSPA 2018 - Photonic Colloidal Nanostructures: Synthesis, Properties, and Applications“", Saint Petersburg, Russia, June 4-8, 2018 формирования, морфологию и выходные характеристики многокомпонентных комплексов.

Одним из таких факторов является химическое окружение нанообъектов в их коллоидных растворах и многокомпонентных материалах. Органические молекулы играют решающую роль в процессах роста нанокристаллов и их самоорганизации [6]. Неудивительно, что свойства гибридных комплексов также в значительной степени определяются функциями органических молекул-лигандов, связывающих их компоненты. Нами было показано, что в отсутствие связывающих молекуллигандов, агрегация КТ и наночастиц золота сопровождается резонансным безызлучательным переносом энергии от нанокристалла к металлической наночастице, что приводит к значительному тушению люминесценции [7]. Такой эффект является нежелательным для дальнейших применений. Следовательно, создание связанных комплексов металлических частиц с полупроводниковыми КТ с улучшенными оптическими параметрами является актуальной задачей.

В данной работе развита методика получения комплексов связанных золотых наночастиц (ЗНЧ) и полупроводниковых КТ градиентного состава (аллоидных) $\mathrm{CdZnSeS} / \mathrm{ZnS}$ (КТ) с использованием молекул карбоксилмеркаптановых кислот и исследована их морфология в сравнении со структурами, полученными в результате смешения исходных коллоидных растворов.

\section{Экспериментальные методы и материалы}

Для изучения морфологии сформированных комплексов был использован сканирующий электронный микроскоп (СЭМ) Merlin (Carl Zeiss). 

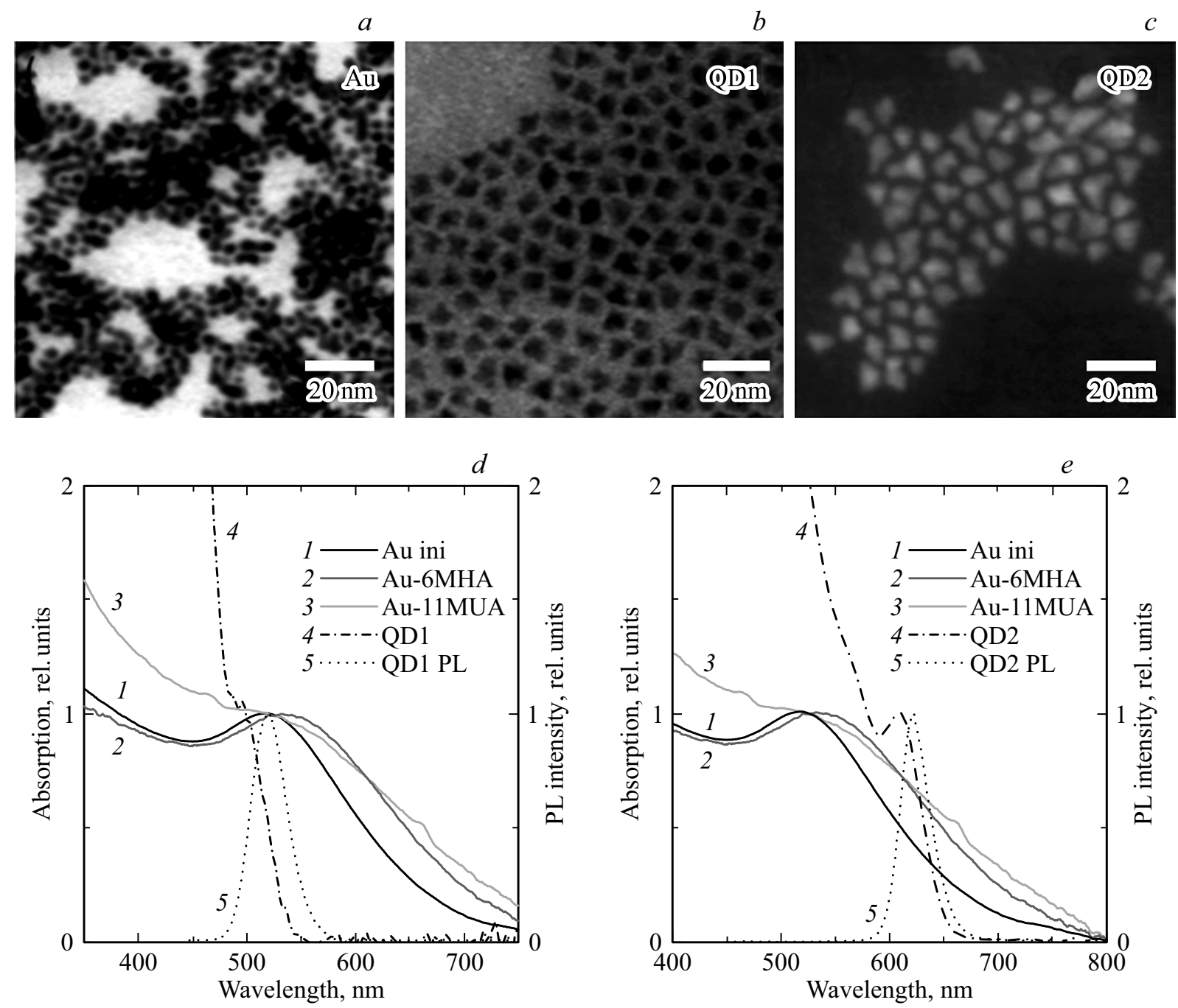

Рис. 1. СЭМ-изображения ЗНЧ (a) и КТ QD1 (b) и QD2 (c), нанесенных из исходных растворов; Спектры поглощения растворов ЗНЧ с разными лигандами (кривые $1-3$, оттенки серого) и спектры поглощения и фотолюминесценции (соответственно штрихпунктир 4 и пунктир 5) KT: $(d)-$ QD1 и $(e)-\mathrm{QD} 2$.

Коллоидные ЗНЧ были синтезированы по методике, описанной в работе [8]. В результате синтеза были получены ЗНЧ с размером $4.0 \pm 0.8 \mathrm{~nm}$, стабилизированные молекулами глутатиона (glutathione, GSH) с длиной цепочки $\sim 1.5 \mathrm{~nm}$. СЭМ-изображение наночастиц приведено на рис. $1, a$. В работе нами были использованы коллоидные КT $\mathrm{CdZnSe} / \mathrm{ZnS}$ градиентного состава с двумя различными процентными соотношениями компонентов для обеспечения люминесценции в зеленой области (QD1) и красной области (QD2). KT были получены методом органо-металлического синтеза в органическом растворе по методике, описанной в работе [9]. В результате синтеза были получены КТ с диаметром $7.0 \pm 1.0 \mathrm{~nm}$, стабилизированные органическими молекулами-лигандами триоктилфосфин оксида (trioctylphosphine oxide, ТОРО) и олеиновой кислоты (oleic acid, OA). Для исключения влияния исходного химического окружения КТ на свойства комплексов и лучшего связывания выбранных молекул-лигандов с КТ их поверхность была очищена от исходных молекул ТОРО и ОА с помощью двукратной обработки метанолом с дальнейшим осаждением КТ центрифугированием на частоте $15000 \mathrm{rpm}$ в течение $5 \mathrm{~min}$. На рис. $1, b, c$ приведены СЭМ-изображения образцов QD1 и QD2. Видно, что коллоидные КТ обладают пирамидальной формой.

ЗНЧ и КТ были выбраны таким образом, чтобы спектральные характеристики отвечали условиям усиления сигнала фотолюминесценции КТ. Спектры поглощения КТ и ЗНЧ и фотолюминесценции КТ приведены на рис. $2, d, e$.

Для получения коллоидных комплексов ЗНЧ и КТ были выбраны связывающие органические молекулы, обладающие двумя активными группами: тиольной $(-\mathrm{SH})$ и карбоксильной $(-\mathrm{COOH})$, которые ковалентно связываются с атомами $\mathrm{Au}$ и $\mathrm{Zn}$ на поверхности НЧ и КТ соответственно. В нашей работе использовались два вида карбоксилмеркаптановых кислот: 6-меркапто- 
$a$

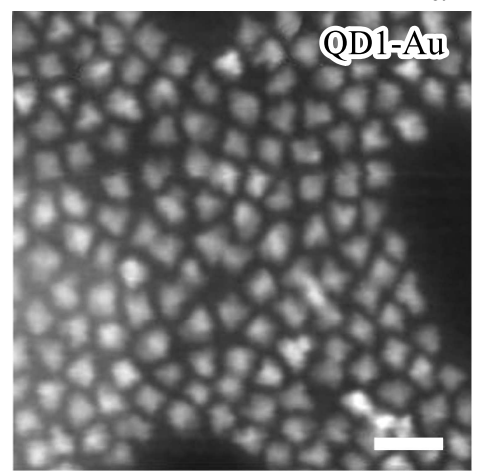

$d$

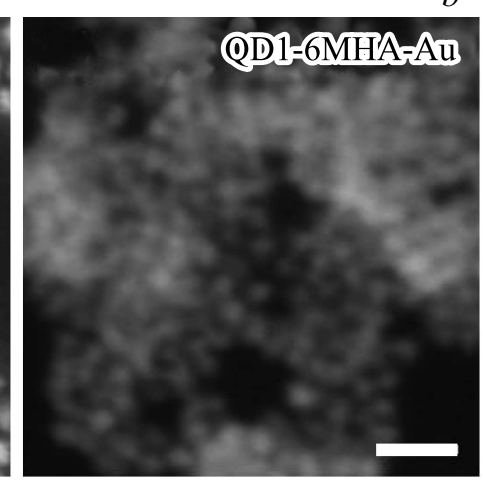

$b$
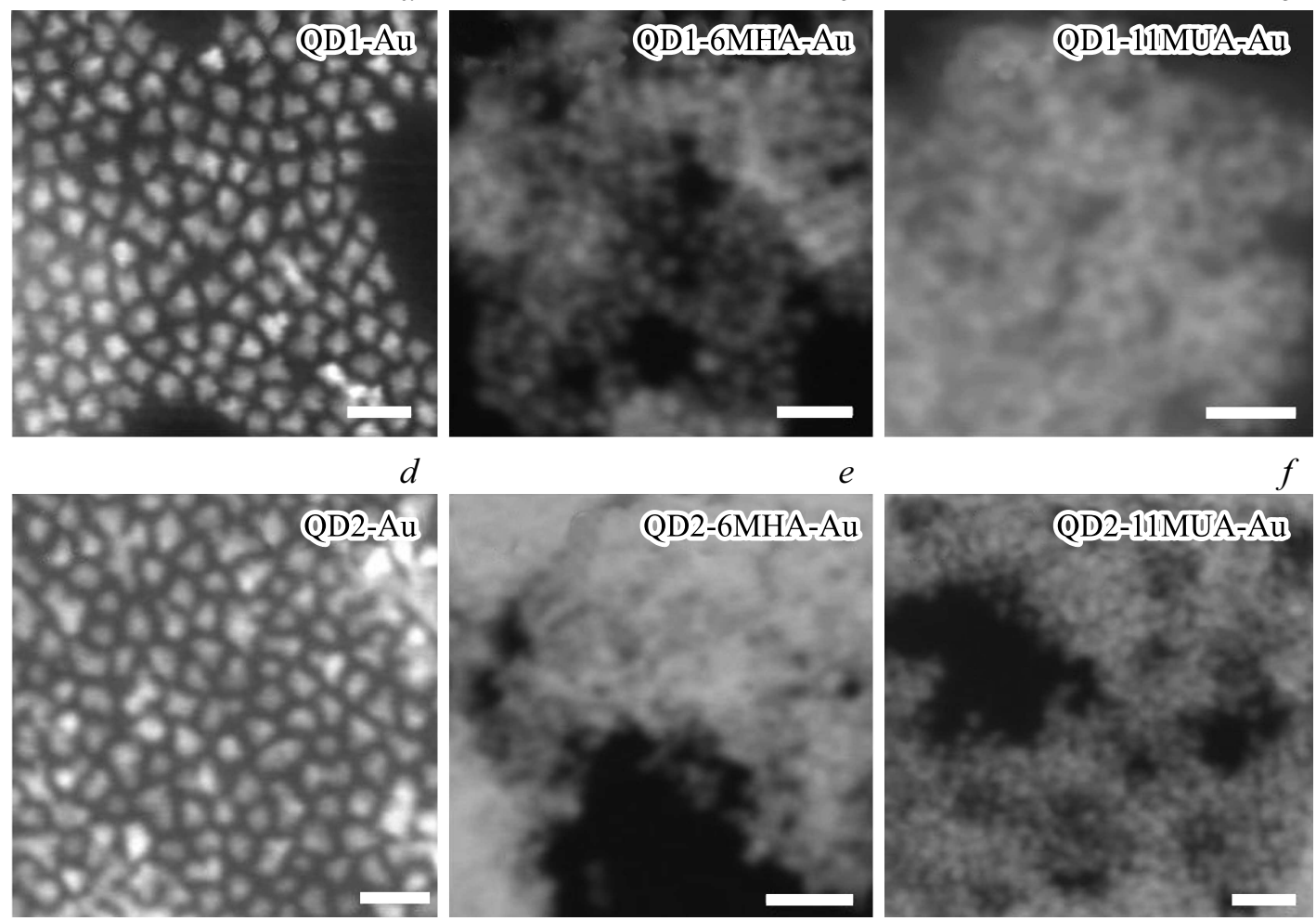

$e$

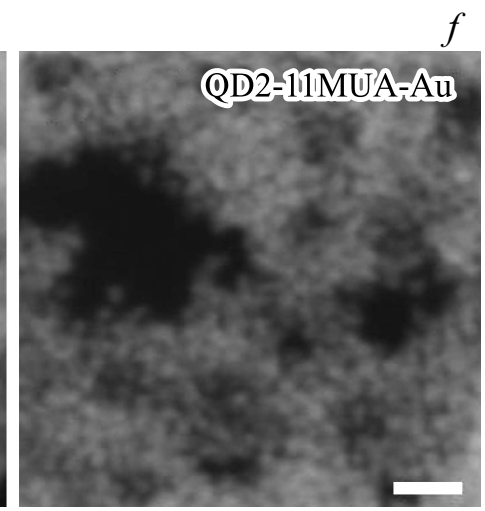

Рис. 2. СЭМ-изображения комплексов, сформированных с KT QD1 $(a-c)$, и QD2 $(d-f)$ при использовании различных связующих лигандов: $\operatorname{GSH}(a, d), 6 \mathrm{MHA}(b, e), 11 \mathrm{MUA}(c, f)$. Длина масштабного отрезка $20 \mathrm{~nm}$.

гексановая кислота (6-mercaptohexanoic acid, 6MHA) и 11-меркаптоундекановая кислота (11-mercaptoundecanoic acid, 11MHА). Для дальнейшего приготовления коллоидных комплексов были использованы растворы $6.4 \mathrm{wt} \%$ 6MНА и $6.3 \mathrm{wt} \%$ 11MUA в этаноле.

\section{Результаты и обсуждение}

Для замены молекул GSH на поверхности ЗНЧ на длинноцепочечные лиганды, $250 \mathrm{ml}$ водного раствора ЗНЧ с добавлением $1 \mathrm{ml}$ изопропанола центрифугировалось на частоте $15000 \mathrm{rpm}$ в течение $5 \mathrm{~min}$. После этого к осадку добавлялось по $200 \mu 1$ растворов кислот. Смесь перемешивалась в течение $15 \mathrm{~h}$, после чего по $50 \mu \mathrm{l}$ раствора ЗНЧ добавлялось в $450 \mu 1$ раствора КТ в толуоле. В результате было получено 6 образцов коллоидных растворов комплексов КТ-ЗНЧ (QD-Au). Для исследования их морфологии полученные коллоидные растворы были нанесены на сетки для электронной микроскопии. На рис. 2 приведены их СЭМ-изображения.

На СЭМ-изображениях комплексов, сформированных с исходным раствором золота (рис. $2, a, d$ ), видны ансамбли частиц, которые состоят практически только из КТ. Невозможно однозначно различить положение ЗНЧ. Можно предположить, что при смешении исходных коллоидных растворов ЗНЧ и КТ в образце QD1$\mathrm{Au}$ не происходит связывания КТ с ЗНЧ, что приводит к организации отдельных ансамблей КТ или ЗНЧ на СЭМсетке. В случае QD2-Аu образец состоит из ансамблей хаотично смешанных сферических и пирамидальных наночастиц, что может свидетельствовать о частичном смешении КТ и ЗНЧ.

СЭМ-изображения комплексов КТ и ЗНЧ, полученных с использованием молекул карбоксилмеркаптановых кислот, являются менее контрастными из-за избытка используемых органических молекул в растворе. Видно, что для всех образцов комплексов с молекулами 6МНА и 11MUA наночастицы образовали разупорядоченные плотноупакованные ансамбли с равномерным распределением ЗНЧ и КТ. Разупорядочение наночастиц в ансамблях связано, скорее всего, с различной формой и размером наночастиц. Полученные коллоидные комплексы являются стабильными и сохраняют свою структуру по крайней мере в течение месяца после образования.

\section{Заключение}

В работе были исследованы люминесцентные комплексы золотых наночастиц и полупроводниковых КТ градиентного состава, связанных молекулами-лигандами карбоксилмеркаптановых кислот с разной длиной цепочки. Показано, что в отсутствие молекул-лигандов, связывающих КТ и золотые наночастицы, образование комплексов не происходит. Использование карбоксил- 
меркаптановых кислот позволяет получить стабильные коллоидные комплексы золотых наночастиц и КТ с равномерным распределением наночастиц в образце.

Данные результаты улучшают понимание процессов в многокомпонентных комплексах и влияние их составляющих на свойства результирующих комплексов. Совершенствование контроля над этими и другими факторами необходимо для успешного внедрения новых материалов в современные оптоэлектронные и биохимические системы.

Авторы благодарят Минобрнауки РФ (грант Президента РФ МК-1757.2017.2) за финансовую поддержку работы. Исследования методом сканирующей электронной микроскопии были проведены с использованием оборудования междисциплинарного ресурсного центра „Нанотехнологии“ Научного парка Санкт-Петербургского государственного университета.

\section{Список литературы}

[1] Petryayeva E. et al. // Appl. Spectrosc. 2013. V. 67. N 3. P. 215-252.

[2] Kovalenko M.V. et al. // ACS Nano. 2015. V. 9. N 2. P. 1012 1057.

[3] Jun S., Jang E. // Angew. Chemie Int. Ed. 2013. V. 52. N 2. P. 679-682.

[4] Costi R. et al. // Nano Lett. 2008. V. 8. N 2. P. 637-641.

[5] Figuerola A. et al. // Nano Lett. 2010. V. 10. N 8. P. $3028-3036$.

[6] Ushakova E.V. et al. // J. Phys. Chem. C. 2016. V. 120. N 43. P. 25061-25067.

[7] Волгина Д.А. и др. // Опт. и спектр. 2018. Т. 124. № 4. C. 477-483.

[8] Dubavik A. et al. // Langmuir 2011. V. 27. N 16. P. 10224-10227.

[9] Bae W.K. et al. // Chem. Mater. 2008. V. 20. № 2. P. 531-539.. 